MURAT DÖRTERLER, Ph.D. ${ }^{1}$

(Corresponding Author)

E-mail: dorterler@gazi.edu.tr

ÖMER FARUK BAY, Ph.D. ${ }^{2}$

E-mail: omerbay@gazi.edu.tr

${ }^{1}$ Department of Computer Engineering, Faculty of Technology, Gazi University 06500, Teknikokullar, Ankara, Turkey

2 Department of Electrical - Electronic Engineering,

Faculty of Technology, Gazi University

06500, Teknikokullar, Ankara, Turkey
Intelligent Transport Systems (ITS)

Preliminary Communication

Submitted: 24 Mar. 2017

Accepted: 27 Nov. 2017

\title{
NEURAL NETWORK BASED VEHICULAR LOCATION PREDICTION MODEL FOR COOPERATIVE ACTIVE SAFETY SYSTEMS
}

\begin{abstract}
Safety systems detect unsafe conditions and provide warnings for travellers to take action and avoid crashes. Estimation of the geographical location of a moving vehicle as to where it will be positioned next with high precision and short computation time is crucial for identifying dangers. To this end, navigational and dynamic data of a vehicle are processed in connection with the data received from neighbouring vehicles and infrastructure in the same vicinity. In this study, a vehicular location prediction model was developed using an artificial neural network for cooperative active safety systems. The model is intended to have a constant, shorter computation time as well as higher accuracy features. The performance of the proposed model was measured with a real-time testbed developed in this study. The results are compared with the performance of similar studies and the proposed model is shown to deliver a better performance than other models.
\end{abstract}

\section{KEY WORDS}

cooperative active safety systems; inter-vehicular communication; vehicular location prediction; artificial neural networks;

\section{INTRODUCTION}

Road transportation has an indispensable role in human life despite all the hitches in economic, environmental and social aspects. Thus, multi-dimensional research and development studies have been carried out for safer and more effective road transportation. Developments in information and communication technologies have been rapidly deployed in road transportations in the last decade.

The main principle of safety applications is that moving vehicles recognize possible dangers and eliminate them. Inter Vehicle Communication (IVC) is one of the approaches that makes the road transportation safer, more efficient and more comfortable via wireless technology. In this approach, vehicles exchange their information such as dynamic and navigational values between each other and road infrastructures. Therefore, IVC makes possible cooperative active safety systems (CASS), which provide more effective safety through cooperation among vehicles and infrastructures.

Not only are data received from the vehicles and the infrastructures in the surrounding area, but also the dynamic and navigational values fetched from the vehicles are processed to recognize the possible dangers.

Real-time estimation of the future geographical position of a vehicle in motion is called vehicular location prediction (VLP). It is also referred to by such terms as state estimation, mobility prediction, path prediction, and vehicle tracking. High precision and short computation times are essential components of VLP models. A perusal of literature shows that state-space equations are commonly used for prediction questions. The matrix algebra used in these equations affects the computation time adversely. In particular, the computation time increases gradually as prediction time interval increases. The VLP methods with long computation times are not convenient. Moreover, the VLP methods with inconstant computation times are much more likely to cause desynchronization between vehicles or devices.

This study focuses on how to conduct VLP with constant, short computation times as well as high accuracy on the highways and the rural roads for CASS. For this purpose, artificial intelligence-based solutions are preferred over state-space-based models. Artificial Neural Network (ANN), which becomes prominent in predicting techniques through artificial intelligence methods, was selected. The development and performance tests were conducted in real world 
environment. A testbed equipped with a Global Navigation Satellite System (GNSS), an Inertial Measurement Unit (IMU) and multithreading software was developed.

The remainder of this paper is organized as follows. In the second Section of the study, VLP and the studies in this field are cited. In the third Section, the proposed model and developing procedures are described. In the fourth Section, the results of the real-time applications and comparisons of the similar studies are explained. The last Section includes the conclusion.

\section{VEHICULAR LOCATION PREDICTION}

IVC is one of the research areas of Intelligent Transportation System (ITS). IVC approach and related studies began in the early 1980s [1]. Thanks to the reduction in the cost of both GNSS receivers and wireless local area networks (WLAN), the studies on IVC became widespread towards the end of the 1990s. These studies aimed to provide a safer travel and an efficient transportation for goods and passengers and to minimize the adverse effects of the transportation on the environment.

The reflection of wireless technologies in IVC field is called Vehicular Ad-Hoc Networks (VANETs). Vehicle-to-Vehicle (V2V) and Vehicle-to-Infrastructure (V2I) communication types are used together or separately in VANETs. The communication in V2V is provided by devices called On-board Units (OBUs). The vehicle communicates with the devices set on roadsides called Roadside Units (RSUs) in V2I. V2I is also known as vehicle to roadside communication (V2R) $[2,3]$.

Multi-faceted studies have been carried out to improve the adverse situations in road transport, especially collisions. The studies on road safety are categorized under two headings; passive and active safety systems. The passive safety systems are designed to prevent people from being injured in collisions, whereas the active systems aim to avoid collisions [4].

The active safety systems can be categorized under two headings, namely autonomous systems and CASS. Autonomous systems collect and analyse the data of the vehicles received from the surrounding area by means of sensors. Autonomous systems activate the processes which eliminate dangers in case of emergency. CASS has highlighted the communication between the vehicles. CASSs collect data through the sensors just like in autonomous systems and they collect data from other vehicles and infrastructure devices in the surrounding area. CASS aims not only to eliminate dangers but also to provide effective transportation $[5,6]$.

The main objectives of IVC safety applications are detecting the possibility of a collision using essential information and warnings and interfering. Estimation of geographical position in the future is a crucial challenge for predicting the possibility of a collision.
The information on geographical position, dynamic status and environmental conditions are needed for VLP.

The key elements in the performance of the VLP are high precision and short computation time. The quality of the sensors and devices as well as the prediction method are vital to achieve these values. This equipment needs to be able to make measurements with both minimum error rate and maximum frequency at high speed. High processing power and high memory capacity are needed for parsing, processing and transmitting a large volume of fetched data.

The computation time as well as the prediction performance of the used method is essential considering today's range of WLAN technologies and vehicle speed. Longer computation times may affect the purpose of safety application adversely. Kalman Filter (KF) is generally used for the solution of estimation problems [7, 8, 9]. However, state-space solutions such as KF have high computation complexity. Furthermore, computation time also increases in estimations based on the time in state-space solutions as the estimation time horizon increases [10].

The studies on VLP can be categorized as deterministic and stochastic approaches. The parameters, considered in the deterministic method, have an important role in determining the prediction method. Vehicles have particular characteristics such as weight, balance, aerodynamic. The method in which these distinctive features of vehicles are taken into consideration is called parametric VLP. The method in which these distinctive features of vehicles are not taken into account and which are used in every vehicle is called non-parametric VLP [11].

The data used in non-parametric methods are limited to the geographical position, velocity, and the curve of the road. The characteristics of the vehicle are ignored. In this way, the method can be used in all vehicles regardless of the brand and the model of the vehicle or without any specific change on the vehicle. However, road level accuracy is figured out via this approach. Hence, these approaches are unsuitable for most of the safety applications, which require the line level accuracy [12].

VLP can be carried out with a movement model developed for vehicle dynamics [13]. Vehicle dynamics involves many parameters, such as geometric structure and tire dynamics. Complex parametric VLP models can be designed as two-state systems or multi-state systems depending on the application developed. The modelling of the vehicle in motion can be designed by a few equations like continuous-time, discrete-time or non-linear equality [12].

Both uncertainties in the vehicle traffic and the noise occurring in sensor measurements show that deterministic methods will not be able to succeed alone. The common method used in stochastic VLP 
is Kalman Prediction. Kalman prediction is one of the three levels of KF, proposed by Rudolph E. Kalman [14]. Kalman prediction can be applied to the linear systems and the linearized non-linear systems.

Chiu-Feng et al. [15] developed algorithms for VLP by means of numerically integrating a linearized 2-DOF model. The authors developed steady-state KF to predict the vehicle's lateral velocity and the magnitudes of external disturbance acting on the vehicle. Hang and Tan $[16,17]$ developed four different methods for VLP by using Kalman prediction. A lot of matrix computation is required at both discretizations of the continuous-time and prediction in Kalman Prediction. These computations need a large amount of computer resources [18].

Barrio et al. [19] proposed an interacting-multiple-model that provided the predicted future location of the vehicle up to $3 \mathrm{~s}$ ahead of time. The model is based on four possible states of a vehicle: constant location, constant velocity, constant acceleration, and constant jerk. Feng et al. [20] proposed a location prediction model applying KF for linear movement. The authors claimed that their model is superior to ANN. Nevertheless, they used three different datasets sampled not only without vehicle dynamics, but also at low frequency. Moreover, the aimed environment, rural or urban, was not mentioned. Jaiswal and Jaidhar [21] proposed a location prediction algorithm using extended KF for a non-linear vehicular movement. They used GNSS traces without vehicle dynamics retrieved haphazardly from OpenStreetMap [22] and VANETMOBISIM [23]. They claimed that their algorithm performed better compared to KF-based prediction. The last three studies did not consider computation time. However, Caveney achieved more accurate location predictions with lower computation time using a numerical integration method [24].

There is a limited number of studies on VLP. On the other hand, many methods have been developed as an alternative or supportive to the $\mathrm{KF}$ in the target tracking systems. An important part of these alternatives is based on artificial intelligent methods such as ANN, genetic algorithm and fuzzy logic [25-27]. In particular, the applicability of ANN on non-linear systems is put forward ANN over KF [28].

\section{PROPOSED VLP MODEL}

An ANN-based model was chosen to achieve the goal of this study. A real time testbed was developed to conduct the development and testing procedures of the model. Many field studies and experiments were conducted to determine the most suitable ANN model.

\subsection{Testbed}

A testbed depicted in Figure 1 was developed, both to get datasets necessary for training the ANN model and to test the real-time performance of the model. The testbed, designed as an OBU, consists of nine parallel processes. These are: Reading geographical position, Reading vehicle dynamics, Prediction on UTM $X$, Prediction on UTM Y, Collision monitoring, Multicast transmitting, Multicast receiving, Logging on file, and Informing over digital map.

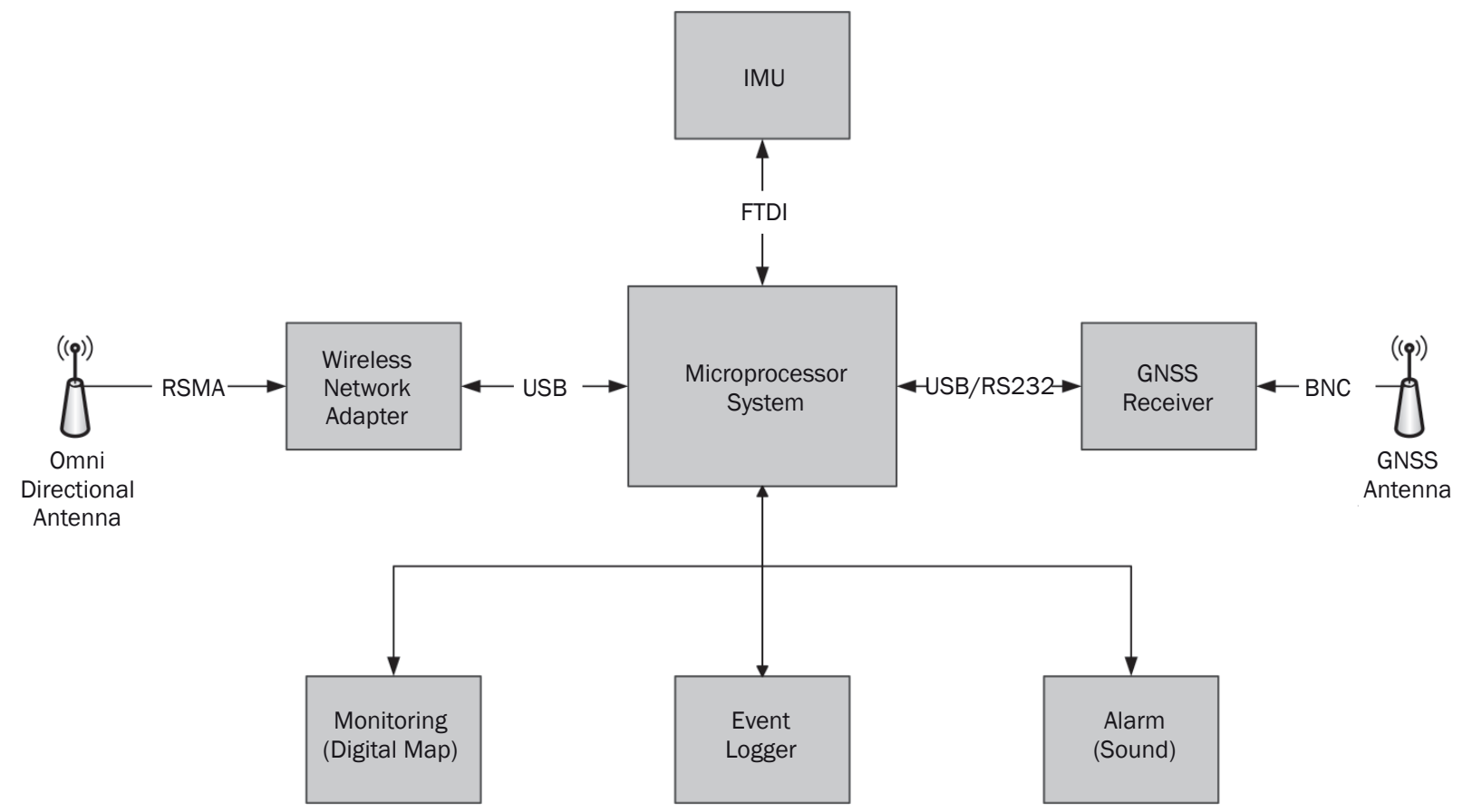

Figure 1 - The block diagram of the testbed 
Novatel FLEXG2-V2-L1 GNSS receiver, which has $40 \mathrm{~cm}$ accuracy and $20 \mathrm{~Hz}$ frequency, is used to measure geographical position, direction and velocity values. Sparkfun LISY300AL gyroscope, which has a scale of $\pm 300 \%$ s and $88 \mathrm{~Hz}$ frequency, is used to measure the orientation of vehicle on 3 axes. Sparkfun MMA7260Q accelerometer, which has $1.5 \mathrm{~g}$ sensitivity and $350 \mathrm{~Hz}$ frequency, is used to measure the acceleration of vehicle on 3 axes. Both the gyroscope and the accelerometer are integrated into Sparkfun atomic DoF IMU.

Multicast data transmission is preferred for V2V communication. Each vehicle is intended to transmit and receive data packets consisting of the current geographical position, velocity, direction, and predicted geographical position of the vehicle in the future. Because there was not any hardware supported IEEE 802.11p standard developed for VANETs on the market, AirLive X.USB-3 WLAN adapters supported by IEEE 802.11a are used with an 8-bdi omnidirectional antenna. The reason for preferring IEEE 802.11a is that it is very similar to IEEE 802.11p standard [29, 30].

An offline digital map was developed to monitor the position and movements of the vehicles in the VANET in real time. The position, velocity, and direction of the vehicles are shown to the driver on the map in real time (Figure 2). Also, the data collected from the measuring instruments and VANET are logged to the filing system at a $50 \mathrm{~Hz}$ frequency rate.

A microprocessor system is available in the centre of the testbed to run the software operating in coordination with the components and the processes mentioned above (Figure 1). A laptop PC with Intel i5 processor, 4 GB memory was used as the microprocessor system. The system software running the testbed was developed using Java programming language with object-oriented programming methods as multithread. The testbed was set up on vehicles and the performance of the testbed was tested in a real-world environment.

\subsection{Development of the proposed model}

Initially, ANN should be trained to solve a problem. A dataset consisting of samples related to how an ANN reacts to which situations is necessary for training the process. The dataset was collected by conducting real-time field applications.

\subsubsection{Collection of data for training}

The datasets are necessary for determining the desired ANN model and for its training. The information in geographical position (UTM X, UTM Y, and altitude), acceleration in three axes (acceleration $X$, acceleration $Y$, acceleration Z), orientation in three axes (yaw, pitch, and roll), velocity (horizontal velocity, vertical velocity) and direction (magnetic north angle) was collected from the vehicle in motion during the field applications.

The study covers rural roads and highways. Therefore, the field studies were conducted on a highway. The field applications were performed in various time periods, directions and velocities on the highway between Ovacık Neighbourhood and Kizilca Village in Ankara. There were 73,909 lines of raw data collected on the highway segment about $48 \mathrm{~km}$ long. Each line was stored in a CSV file format as shown below.

\$timestamp, UTM X, UTM Y, altitude, acceleration $X$, acceleration $Y$, acceleration $Z$, yaw, pitch, roll, horizontal velocity, direction, vertical velocity

\subsubsection{Training of ANN}

Several experiments were performed to identify the aimed ANN model most accurately with the lowest computation time. It was the objective of the study to determine the learning method, activation function, and the number of layers as well as input-output data types and formats of the ANN model used in the experiments. Each experiment consisted of four sequential processes. These processes were the preparation of the dataset, determination of the ANN structure, training of the ANN and evaluation of the results.

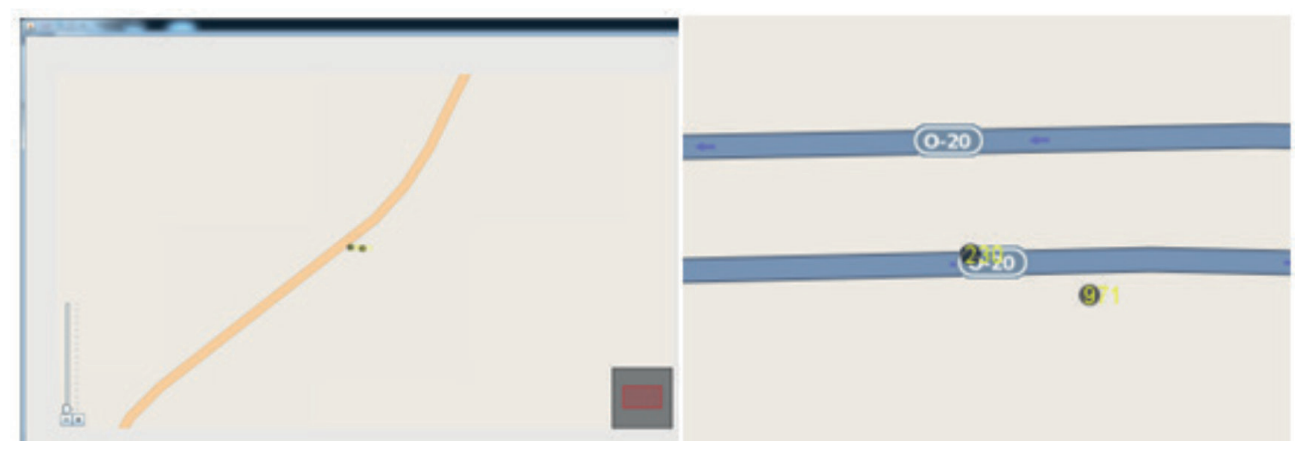

Figure 2 - The navigation of two vehicles in motion is monitored on a digital map of the testbed in different zoom levels 
A utility software was developed for a successful and quick execution of the processes using Java programming language (Figure 3). A MATLAB Neural Network Toolbox was used in the infrastructure of the utility. The training functions coded in MATLAB environment were embedded into the utility by converting Java class in MATLAB Builder JA.

A supervised learning method was used in the intended ANN model. The ANN needs to be trained using a dataset consisting of the right input and output values to achieve the expected results. The aim was to predict the distance which the vehicle covers in the horizontal plane during a specific time interval as an output of the suggested ANN model. The subtraction of the values in UTMX and UTMY axes of the geographical position of vehicles between $t$ and $t+n$ moments was computed for the measurement of the covered distance. These distances were used as the output values of ANNs.

We searched for the suitable data types and their format to get the expected output in the experiments. The datasets were prepared using various normalizations and filtering methods in different data types in the inputs and outputs of the ANN. The training dataset consisted of 10,000 lines selected from the collected data randomly.

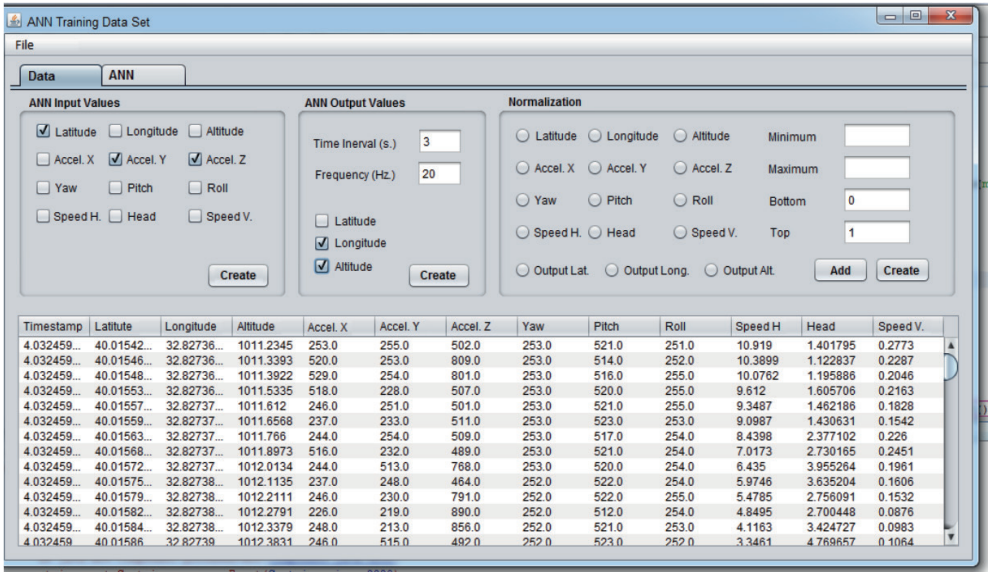

Figure 3 - Data processing interface of the utility software used in ANN experiments

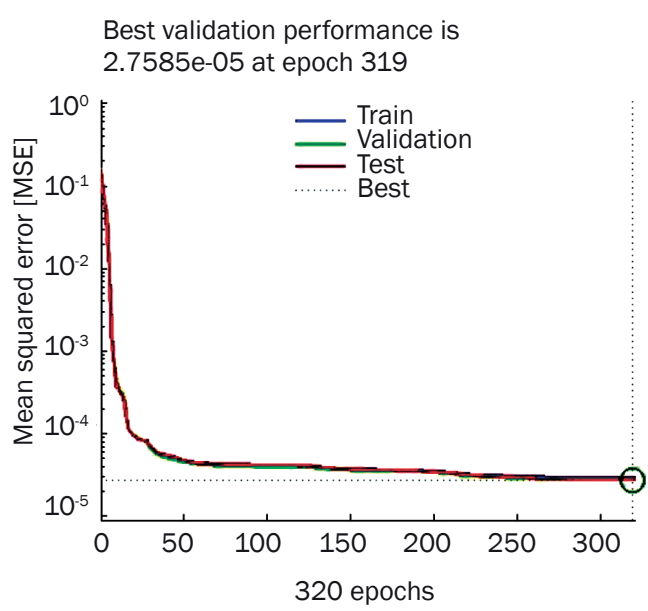

a) The training performance
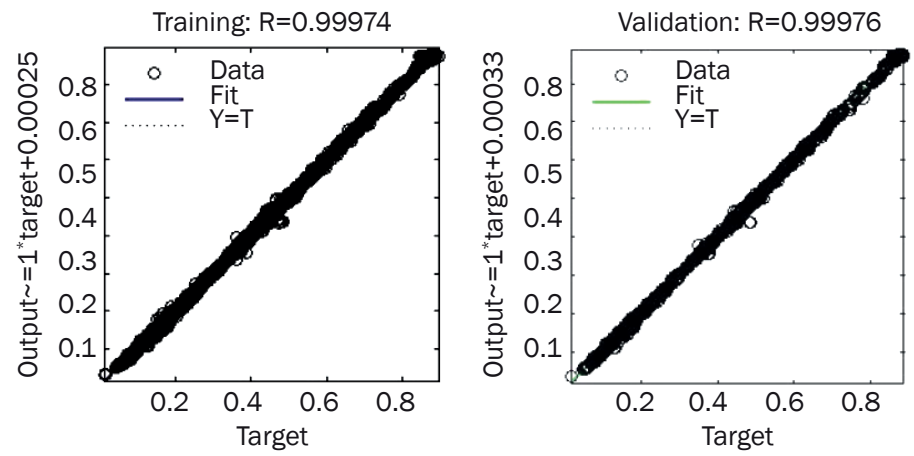

Test: $\mathrm{R}=0.99975$
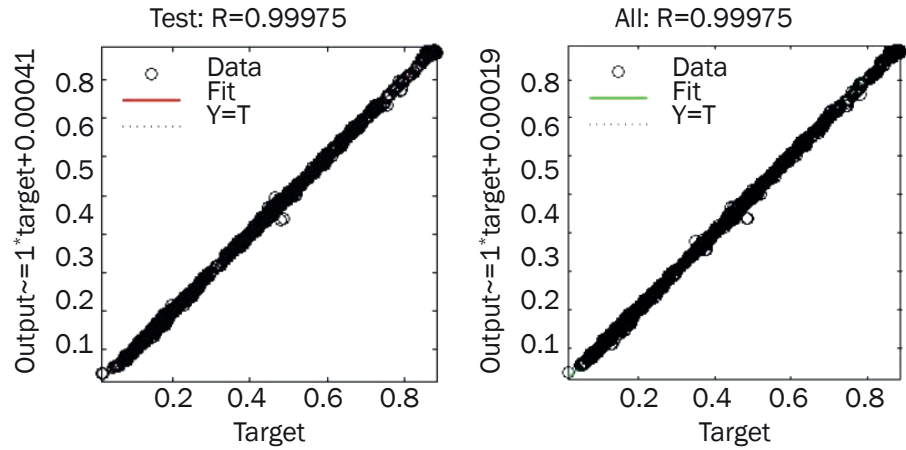

b) The training regression analyses

Figure 4 - Analyses of the ANN, which predicts in 3 seconds time horizon on UTM-Y axis 
Many combinations were tried to determine the network type, the learning method, the activation function, the number of layers and the number of neurons of the ANN model. ANN models which have different structures were trained using the prepared training datasets. Shown in Figure 4 is the training performance of an ANN which predicts in 3-second time intervals on UTM $Y$ axis. The regression graph between prediction results of the same ANN and actual values on each of the three datasets are presented in Figure 4.

\subsection{The proposed ANN-based VLP Model}

At least two values are needed to predict the geographical position of the vehicle in the future as an output of the ANN model. The experiments showed that using two ANNs with a single output yields more accurate results than using a single ANN with two outputs for UTM-X and UTM-Y. Therefore, a pair of ANN running in synchronization with each other were used in the prediction model with the ANN developed (Figure 5). The ANN pairs are created for the prediction of the time interval in which the distance will be covered by the vehicle.

The data collected in the field studies indicate that there was a proportional correlation between the distance previously covered and the distance to be covered afterwards by the vehicle at UTM-X or UTM-Y. The data of navigation performed at $67 \mathrm{~km} / \mathrm{h}$ were analysed. The distance covered in the last one second and the distance to be covered in the next five seconds by the vehicle at any moment were normalized with regard to the speed. It is observed that the rates of the

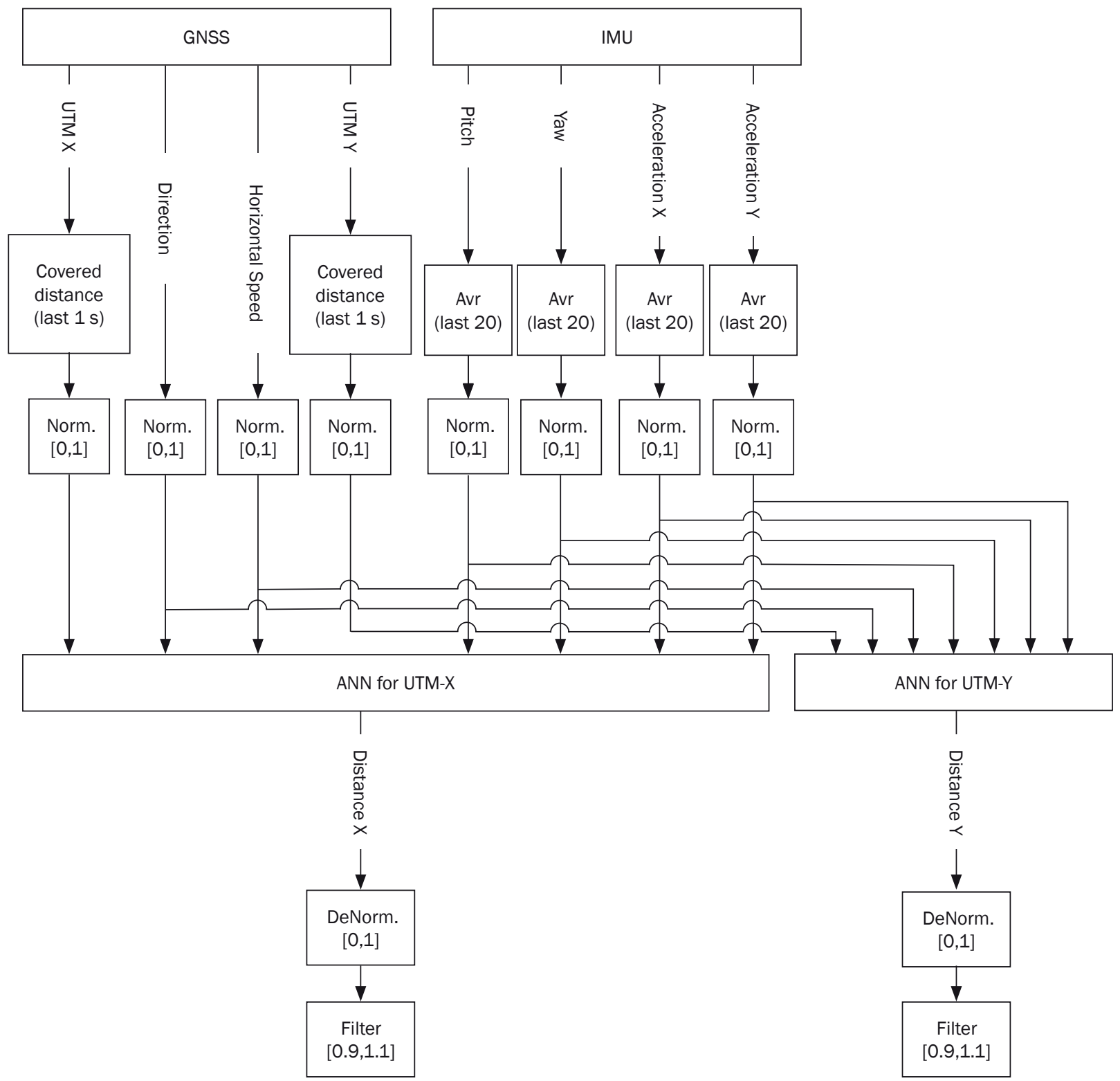

Figure 5 - Input and output data of the ANN model and their types 


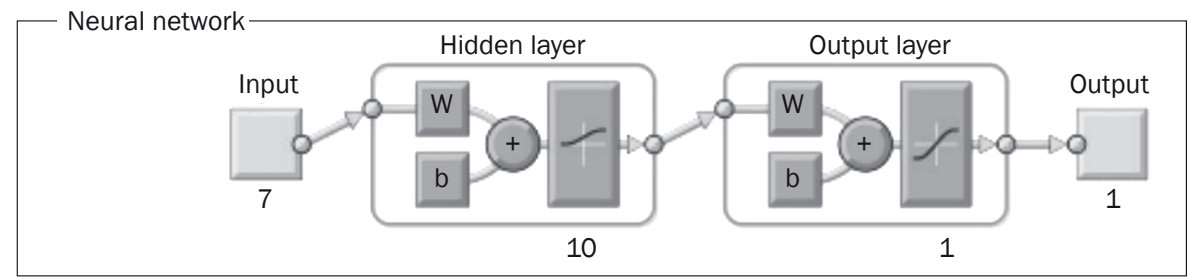

Figure 6 - The structure of the ANN used for prediction on single axis

normalized values ranged between 0.90 and 1.10 in $96 \%$ of all the values. Consequently, it is concluded that normalized covered distance value in the last one second on UTM axis needed to be one of the input values of the ANN. In addition to that, a filter which trims the ratio of the previously measured distance to the predicted values within the range of 0.90 and 1.10 was added to the end of the ANN.

Other data inputs of the ANN pair are common. These common input data consist of accelerations, yaw, horizontal speed and vehicle direction, all of which describe the motion of the vehicle in two-dimensional horizontal plane. In addition, the roll data, one of the vehicle's three-dimensional motion data, are also chosen as input of the ANNs, where the slant constructions of the roads on the curves are taken into consideration.

Mean, normalization and filtering processes were applied to raw input and output values. The acceleration, yaw and roll data received from IMU were not used directly due to the shock sensitivity and high frequency measurement attributes of the IMU. Instantaneous values were received from IMU with $50 \mathrm{~Hz}$ frequency. The arithmetic mean of the values in the last one second was determined as the input values of the ANNs. This approach affected the performance of the ANN positively. The minimum and maximum values of each data type used as input or output value of the ANNs were determined according to the current conditions of the vehicle. They were normalized in the range of $[0$, 1]. The instances with values out of the range calculated as a result of the normalization procedure were not included in the training dataset. The input and output training datasets were created by means of a random selection of the remaining instances.

As a result of the experiments, the ANN type of feed-forward back-propagation neural network was found to give the best results. Levenberg-Marquardt algorithm (LM) [31], one of the second-order algorithms, was selected as the learning method. These algorithms have a significantly high training speed [32]. The LM algorithm has fast and stable convergence on networks which contain up to a few hundred weights [33]. LM offers increased efficiency especially when high precision is required [31]. The log-sigmoid in the hidden layer and the tangent sigmoid in the output layer gave the best results (Figure 6). The developed
ANN pairs were converted into a Java class and embedded into the testbed using a MATLAB Builder JA tool.

\section{PERFORMANCE EVALUATION OF THE PROPOSED MODEL}

Real-time field studies were carried out to determine the performance of the developed ANN-based VLP model. In terms of accuracy and computation time, the performance of the model was construed according to the obtained measurements. The performance values were compared to similar studies.

\subsection{Field studies}

Five ANN pairs were trained according to the proposed model for prediction at each second in the future between $1 \mathrm{~s}$ and $5 \mathrm{~s}$. The trained ANN pairs were converted into Java class by MATLAB Builder JA to build in the testbed. Thus, the target system for the testbed was made ready for both hardware and software by applying the ANN model. Field studies were carried out to test the performance on the highway between Yeni Bayindir Village and Kurucay Village in Ankara (Figure 7a). The highway segment was out of scenes used in the previous field studies to create the training datasets. In the first part of the studies, the testbed was examined with all the functions and in the second part of the studies, the performance of the ANN model was measured.

Two vehicles were equipped with the testing devices developed for the field studies (Figure $7 b$ ). All the parallel processes of the testbed, especially ones related to VLP, were examined with vehicles in motion in real time on the highway. The parallel processes were found to perform uninterruptedly and seamlessly on both vehicles as a result of the first study. The positions of both vehicles were monitored on the digital map (Figure 2).

Two vehicles toured across the highway segment three times for measuring performance of the ANN model. They performed at different average velocities at $45 \mathrm{~km} / \mathrm{h}, 55 \mathrm{~km} / \mathrm{h}$ and $67 \mathrm{~km} / \mathrm{h}$ each time. The vehicles covered a distance of $30 \mathrm{~km}$ in total. The navigational data and predicted values of the five ANN pairs were recorded to evaluate the performance. In 


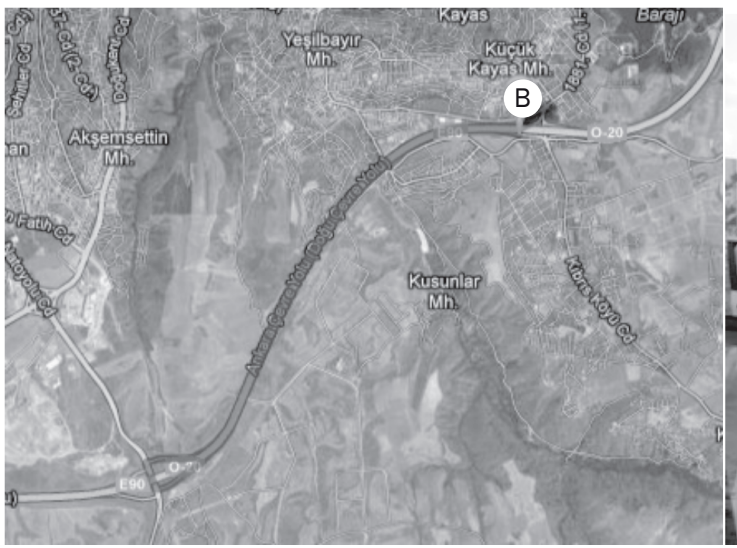

a)

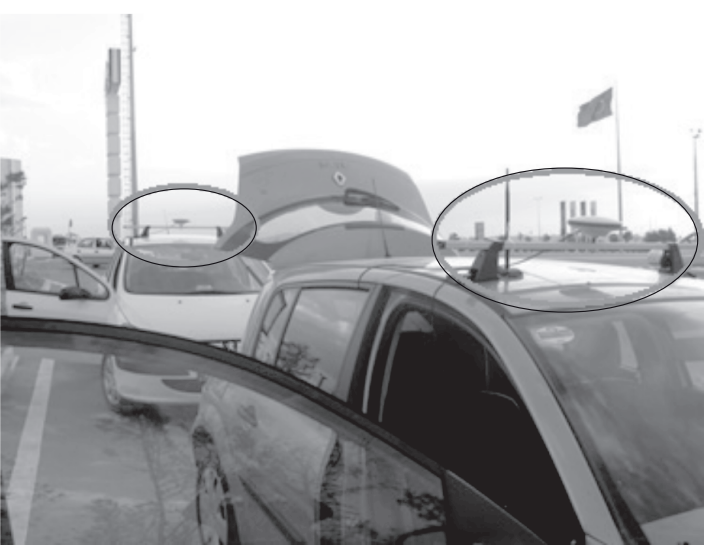

b)

Figure 7 - a) The route used in field studies for performance tests, b) The equipped vehicles used in filed studies

order to make a comparison, the velocity values and route values were chosen similar to the ones used in the studies in literature.

\subsection{Performance and comparisons}

Similar studies in literature were surveyed for performance measurement of the proposed VLP model. The experiments carried out by Caveney [34] were concluded to be the most appropriate studies for comparison. He claimed that KF method commonly used in prediction studies has a shorter computation time and also lower accuracy. In addition, he suggested the Unscented Transform with Numerical Integration (UT-NI) method for location prediction with low computation time and high accuracy.

He further claimed that computation time decreases significantly owing to low memory requirement of UT-NI method. Moreover, it is stated that Route Mean Square (RMS) of prediction accuracy is lower with this method. He carried out VLP with the two methods in the field studies and compared the results (Table 1).

The needed time horizon for location prediction is ranked according to many factors, such as type of the safety application, vehicle speed and environmental factors. Although there is no certain view related to what the time horizon is in which conditions before the danger occurs, the horizon time is commonly determined between one and five seconds in various safety applications [35].

Position-accuracy of the proposed ANN model is determined by Equation 1 at specific velocity for a specific horizon time.

$$
\begin{aligned}
& A_{p}=\sqrt{A_{x}^{2}+A_{y}^{2}} \\
& A_{x}=\sqrt{\frac{1}{n} \sum_{i=1}^{n} x_{i}-\widehat{x}_{i}} \\
& A_{y}=\sqrt{\frac{1}{n} \sum_{i=1}^{n} y_{i}-\widehat{y}_{i}}
\end{aligned}
$$

where $n$ represents the number of sample; $\widehat{x}_{i}$ is the predicted position, and $x_{i}$ is the measured location on UTM-X axis; $\widehat{y}_{i}$ is the predicted position and $y_{i}$ is the real position on UTM-Y axis for the same time; $A_{x}$ and $A_{y}$ are RMS of the errors on both UTM axes. $A_{p}$ is the calculated position accuracy of the proposed model.

Position-accuracy of the proposed ANN model was calculated by using the logged data during the last field study at three different velocities for the five horizon times (Table 2).

The RMS values of position-accuracy of KF, UT-NI and proposed ANN methods are compared in Table 3.

Table 1 - Position-accuracy comparison for the Kalman prediction and UT-NI approaches for various average vehicle speeds [34]

\begin{tabular}{||c|c|c|c|c|c|c||}
\hline \multirow{3}{*}{ Approach } & \multirow{2}{*}{$\begin{array}{c}\text { Speed } \\
{[\mathrm{km} / \mathrm{h}]}\end{array}$} & \multicolumn{5}{|c|}{ Prediction horizon [m] } \\
\cline { 2 - 7 } & 45 & $1 \mathrm{~s}$ & $2 \mathrm{~s}$ & $3 \mathrm{~s}$ & $4 \mathrm{~s}$ & $5 \mathrm{~s}$ \\
\hline \hline \multirow{3}{*}{ Kalman } & 45 & 0.26 & 1.27 & 3.45 & 6.94 & 11.7 \\
\cline { 2 - 8 } & 57 & 0.56 & 2.07 & 5.26 & 10.4 & 17.4 \\
\hline \multirow{3}{*}{ UT-NI } & 45 & 0.72 & 2.41 & 6.01 & 12.1 & 20.8 \\
\cline { 2 - 8 } & 55 & 0.32 & 1.13 & 3.07 & 6.08 & 8.46 \\
\cline { 2 - 8 } & 67 & 0.47 & 1.57 & 4.51 & 8.04 & 9.92 \\
\hline
\end{tabular}


Table 2 - Position-accuracy for the Proposed ANN Model for various average vehicle speeds

\begin{tabular}{||c|c|c|c|c||}
\hline $\begin{array}{c}\text { Time } \\
{[\mathrm{s}]}\end{array}$ & $\begin{array}{c}\text { Speed } \\
{[\mathrm{km} / \mathrm{h}]}\end{array}$ & $\begin{array}{c}A_{x} \\
{[\mathrm{~m}]}\end{array}$ & $\begin{array}{c}A_{y} \\
{[\mathrm{~m}]}\end{array}$ & $\begin{array}{c}A_{p} \\
{[\mathrm{~m}]}\end{array}$ \\
\hline \hline \multirow{3}{*}{1} & 45 & 0.4488 & 0.4729 & 0.6520 \\
\cline { 2 - 5 } & 55 & 0.4964 & 0.5118 & 0.7130 \\
\cline { 2 - 5 } & 67 & 0.5395 & 0.5790 & 0.7914 \\
\hline \multirow{3}{*}{2} & 45 & 0.7469 & 0.7548 & 1.0619 \\
\cline { 2 - 5 } & 55 & 0.8423 & 0.8105 & 1.1689 \\
\cline { 2 - 5 } & 67 & 0.9424 & 0.8983 & 1.3020 \\
\hline \multirow{3}{*}{3} & 45 & 1.1129 & 1.1295 & 1.5857 \\
\cline { 2 - 5 } & 55 & 1.2215 & 1.2153 & 1.7231 \\
\cline { 2 - 5 } & 67 & 1.3569 & 1.2826 & 1.8671 \\
\hline \multirow{3}{*}{4} & 45 & 1.4347 & 1.4738 & 2.0568 \\
\cline { 2 - 5 } & 55 & 1.6031 & 1.5526 & 2.2317 \\
\cline { 2 - 5 } & 67 & 1.7483 & 1.6682 & 2.4165 \\
\hline \multirow{3}{*}{5} & 45 & 1.9070 & 2.0151 & 2.7744 \\
\cline { 2 - 5 } & 55 & 2.1870 & 2.0908 & 3.0256 \\
\cline { 2 - 5 } & 67 & 2.4011 & 2.2093 & 3.2629 \\
\hline \hline
\end{tabular}

Table 3 shows that the error rates of the predictions increase as the time horizon or speed increase in each of the three methods. The increase in the error rate in the predictions where the ANN model was used was lower than that of the others when the error rates in connection with the time horizon and the speed in all of the three methods were compared. In addition, more successful results were obtained in time horizons of 3 seconds and above with the proposed ANN method in comparison with other methods. The accuracy of the proposed ANN method was lower at 1-second and 2-second time horizons than the accuracy of other methods. The failure of the proposed method in the shorter time horizon predictions can be neglected because the difference between the compared values was low and the scope of the study covered highway and rural ways transportation only.

Table 4 presents the computation times of the methods for horizon times from $1 \mathrm{~s}$ to $5 \mathrm{~s}$ at $55 \mathrm{~km} / \mathrm{h}$. The computation time of a VLP method must be constant and short for the CASS safety applications. A deficiency of these features can lead to catastrophic results. Variable computation time is much more likely to cause desynchronization between the components of the systems. On the other hand, higher computation time can cause failure to detect dangers in time.

The computation times of both KF and UT-NI methods increase gradually as horizon time increases. Thus, their scores are higher and variable. The values were computed by MATLAB R2006 installed on a machine with a $2.13 \mathrm{GHz}$ CPU, $2 \mathrm{~GB}$ memory and $2 \mathrm{MB}$ cache [24]. The computation time of the proposed ANN model did not change with the prediction horizon. Moreover, the computation time of the proposed model was found to be lower than that of others. The scores of the proposed model were computed by MATLAB R2011a installed on a machine with a $2.5 \mathrm{GHz}$ CPU, 4 GB memory and 3 MB cache.

Table 3 - Position-accuracy comparison of the Kalman prediction, UT-NI and Proposed ANN Model approaches for various average vehicle speeds

\begin{tabular}{||c|c|c|c|c|c|c||}
\hline \multirow{2}{*}{ Approach } & \multirow{2}{*}{$\begin{array}{c}\text { Speed } \\
{[\mathrm{km} / \mathrm{h}]}\end{array}$} & \multicolumn{5}{|c||}{ Prediction horizon [m] } \\
\cline { 3 - 8 } & & $1 \mathrm{~s}$ & $2 \mathrm{~s}$ & $3 \mathrm{~s}$ & $4 \mathrm{~s}$ & $5 \mathrm{~s}$ \\
\hline \hline \multirow{3}{*}{ Kalman prediction [34] } & 45 & 0.26 & 1.27 & 3.45 & 6.94 & 11.7 \\
\cline { 2 - 8 } & 55 & 0.56 & 2.07 & 5.26 & 10.4 & 17.4 \\
\cline { 2 - 8 } & 67 & 0.72 & 2.41 & 6.01 & 12.1 & 20.8 \\
\hline \multirow{3}{*}{ UT-NI [34] } & 45 & 0.30 & 0.67 & 1.74 & 3.60 & 5.86 \\
\cline { 2 - 8 } & 55 & 0.32 & 1.13 & 3.07 & 6.08 & 8.46 \\
\cline { 2 - 8 } & 67 & 0.47 & 1.57 & 4.51 & 8.04 & 9.92 \\
\hline \multirow{3}{*}{ Proposed ANN Model } & 45 & 0.6520 & 1.0619 & 1.5857 & 2.0568 & 2.7744 \\
\cline { 2 - 8 } & 55 & 0.7130 & 1.1689 & 1.7231 & 2.2317 & 3.0256 \\
\cline { 2 - 8 } & 67 & 0.7914 & 1.3020 & 1.1876 & 2.4165 & 3.2629 \\
\hline
\end{tabular}

Table 4 - Computation time comparison for the Kalman prediction, UT-NI and Proposed ANN Model approaches at 55 $\mathrm{km} / \mathrm{h}$ average vehicle speeds

\begin{tabular}{||l|c|c|c|c|c|c||}
\hline \multirow{2}{*}{\multicolumn{1}{|c|}{ Approach }} & \multirow{2}{*}{$\begin{array}{c}\text { Speed } \\
{[\mathrm{km} / \mathrm{h}]}\end{array}$} & \multicolumn{5}{c||}{ Computation time [ms] } \\
\cline { 3 - 8 } & & $1 \mathrm{~s}$ & $2 \mathrm{~s}$ & $3 \mathrm{~s}$ & $4 \mathrm{~s}$ & $5 \mathrm{~s}$ \\
\hline \hline Kalman filter [24] & 55 & 9.7 & 18.5 & 27.5 & 36.4 & 45.0 \\
\hline UT-NI [24] & 55 & 23.1 & 36.9 & 49.1 & 63.8 & 87.7 \\
\hline Proposed ANN Model & 55 & 3.2 & 3.2 & 3.2 & 3.2 & 3.2 \\
\hline
\end{tabular}




\section{CONCLUSION}

This study focuses on the VLP, the keystone of cooperative active safety systems. One of the artificial intelligent methods, ANN was used for location prediction procedures. Several dataset models and ANN attributes were practiced to determine the most suitable ANN model. A utility software was developed to perform the experiments quickly and effectively. A most suitable ANN model determined as a result of the experiments conducted in a real-world environment by means of a real-time testbed was developed. The results obtained from the experiments were compared to similar studies.

As the computation time of the proposed ANNbased VLP model is lower, the usability of the model is higher. Furthermore, the model provides significant advantages in both in-vehicle and inter-vehicle coordination, because the computation time of the model is constant in contrast with other models. The proposed model, which was operated in time horizons of two seconds and above, gives more accurate results than other models do in predictions. The difference in precision does not exceed $40 \mathrm{~cm}$ when compared with the prediction results of the models for both the speeds of 1-second time horizon and $45 \mathrm{~km} / \mathrm{h}$ and $55 \mathrm{~km} / \mathrm{h}$ of 2-second time horizon. This negativity is negligible as far as the gains of the method and the braking distance of the vehicle at these speeds are concerned.

Research opportunities in IVC field are likely to increase with the spread of current technologies. Many applications will be developed in the areas of transportation safety, productivity and entertainment as the roads get equipped with intelligent systems. In the future, we are going to plan the development of crash avoidance applications, utilizing the proposed VLP model. In this regard, a number of field studies will be performed according to the scenarios, criteria and metrics described in the study [35]

\section{ACKNOWLEDGEMENT}

The authors acknowledge the Gazi University Scientific Research Foundation (under 07/200-05), which financed the research activities

\footnotetext{
MURAT DÖRTERLER, Ph.D. ${ }^{1}$

E-mail: dorterler@gazi.edu.tr ÖMER FARUK BAY, Ph.D. ${ }^{2}$

E-mail: omerbay@gazi.edu.tr

1 Bilgisayar Mühendisliği Bölümü, Teknoloji Fakültesi, Gazi Üniversitesi 06500, Teknikokullar, Ankara, Türkiye

2 Elektrik-Elektronik Mühendisliği Bölümü, Teknoloji Fakültesi, Gazi Üniversitesi

06500, Teknikokullar, Ankara, Türkiye
}

\section{IŞBIRLIKÇI ETKIN GÜVENLIK SISTEMLERI IÇIN SINIR AĞI TABANLI TAŞIT KONUMU KESTIRIM MODELI}

\section{ÖZET}

Güvenlik sistemleri, tehlike durumlarını tespit ederler ve yolcuları önlem almaları ve çarpışmadan kaçınmaları için uyarırlar. Tehlikelerin tespiti için seyir halindeki taşıtın gelecekteki coğrafi konumunun yüksek hassasiyet ve düşük hesap zamanı ile tahmini çok önemlidir. Bu amaçla, bir taşıtın seyir ve dinamik verileri komşu tașıtlardan ve alt yapıdan alınan verilerle birlikte işlenmektedir. Bu çalışmada, işbirlikçi etkin güvenlik sistemleri için yapay sinir ağı kullanılarak bir taşıt konumu kestirim modeli geliștirilmiștir. Bu modelin sabit ve düşük hesap zamanı ile birlikte yüksek doğruluk özelliklerine sahip olması amaçlanmıştır. Önerilen modelin başarımı, bu çalıșmada geliştirilen bir gerçek zamanlı test ortamı ile ölçülmüştür. Sonuçlar benzer çalışmaların başarımı ile karşılaştırılmış ve önerilen modelin diğer modellerden daha iyi sonuçlar sunduğu gösterilmiştir.

\section{ANAHTAR KELIMELER}

Işbirlikçi etkin güvenlik sistemleri; Taşıtlar arası iletişim; Taşıt korumu kestirimi; Yapay sinir ağları;

\section{REFERENCES}

[1] Kawashima H. Japanese perspective of driver information systems. Transportation. 1990;17(3): 263-284.

[2] Baldessari R, Bödekker B, Deegener M, et al. Car to Car Communication Consortium Manifesto: Overview of the C2C-CC System. Car to Car Communication Consortium; 2007.

[3] Harding J, Powell G, Yoon R, et al. Vehicle-to-vehicle communications: Readiness of V2V technology for application. Washington, DC: National Highway Traffic Safety Administration; 2014. p. 1-14.

[4] Jarasuniene A, Jakubauskas G. Improvement of road safety using passive and active intelligent vehicle safety systems. Transport. 2007;22(4): 284-289.

[5] Andersen J, Kalra N, Stanley K, Sorensen P, Samaras C, Oluwatola O. Autonomous vehicle technology. $1^{\text {st }}$ ed. Santa Monica, CA: RAND; 2016.

[6] Misener JA. Vehicle-infrastructure integration (VII) and safety: rubber and radio meets the road in California. Intellimotion. 2005:11(2): 1-3.

[7] Vanajakshi L, Subramanian SC, Sivanandan R. Travel time prediction under heterogeneous traffic conditions using global positioning system data from buses. IET Intelligent Transport Systems. 2009;3(1): 1-9.

[8] Barimani N, Rahimi KA, Moshiri B. Real time adaptive non-linear estimator/predictor design for traffic systems with inadequate detectors. IET Intelligent Transport Systems. 2014;8(3): 308-321.

[9] Lu G, Kong L, Wang Y, Tian D. Vehicle trajectory extraction by simple two-dimensional model matching at low camera angles in intersection. IET Intelligent Transport Systems. 2014;8(7): 631-638.

[10] Dhaouadi R, Mohan N, Norum L. Design and implementation of an extended Kalman filter for the state estimation of a permanent magnet synchronous motor. IEEE Transactions on Power Electronics. 1991;6 (3): 491-497. 
[11] Hartenstein H, Laberteaux K. Vehicular applications and inter-networking technologies. $1^{\text {st }}$ ed. Oxford: Wiley-Blackwell; 2010.

[12] Caveney D. Collision avoidance enabled through geospatial positioning and inter-vehicular communications. IEEE Control Systems Magazine. 2010;30(4): 38-53.

[13] Lefèvre S, Vasquez D, Laugier C. A survey on motion prediction and risk assessment for intelligent vehicles. Robomech Journal. 2014;1(1): 1-14.

[14] Sorenson HW. Kalman Filtering: Theory and Application. $1^{\text {st }}$ ed. New York: IEEE Press; 1985.

[15] Lin CF, Ulsoy AG, LeBlanc DJ. Vehicle dynamics and external disturbance estimation for vehicle path prediction. IEEE Transactions on Control Systems Technology. 2000;8(3): 508-518.

[16] Huang J, Tan HS. Vehicle Future Trajectory Prediction with A DGPS/INS-Based Positioning System. Proceedings of the American Control Conference, Jun 2006, Minneapolis. USA. IEEE; 2006.

[17] Tan H-S, Huang J. DGPS-based vehicle-to-vehicle cooperative collision warning: Engineering feasibility Viewpoints. IEEE Transactions on Intelligent Transportation Systems. 2006;7(4):415-428.

[18] Hsu L, Chen T. Vehicle Full-State Estimation and Prediction System Using State Observers. Vehicular Technology. 2009;58(6): 2651-2662.

[19] Barrios C, Motai Y. Improving estimation of vehicle's trajectory using the latest global positioning system with Kalman filtering. IEEE Transactions on Instrumentation and Measurement. 2011;60(12): 3747-3755.

[20] Feng H, Liu C, Shu Y, Yang OW. Location prediction of vehicles in VANETs using a Kalman filter. Wireless Personal Communications. 2015;80(2): 543-559.

[21] Jaiswal RK, Jaidhar CD. Location prediction algorithm for a nonlinear vehicular movement in VANET using extended Kalman filter. Wireless Networks. 2017;23(7): 2021-2036.

[22] Haklay MM, Weber P. Openstreetmap: User-generated street maps. IEEE Pervasive Computing. 2008;7(4): 12-18.

[23] Härri J, Filali F, Bonnet C, Fiore M. Vanetmobisim: Generating realistic mobility patterns for VANETs. Proceedings of the $3^{\text {rd }}$ International workshop on vehicular ad hoc networks, Sep 24-29 2006, Los Angeles, CA, USA. New York: ACM, 2006.
[24] Caveney D. Stochastic Path Prediction using the Unscented Transform with Numerical Integration, Proceedings of the IEEE Intelligent Transportatıon Systems Conference, Sep 30-Oct 3 2007, Bellevue, WA, USA. Los Alamitos: IEEE; 2007.

[25] Turkmen I, Guney K, Karaboga D. Genetic Tracker with Neural Network for Single and Multiple Target Tracking. Neurocomputing. 2006;69(16-18): 2309-2319.

[26] Duh FB, Lin CT. Tracking a maneuvering target using neural fuzzy network systems. Man and Cybernetics Part B: Cybernetics. 2004;34(1): 16-33.

[27] Zhu AF, Jing ZR, Chen WJ. Maneuvering Target Tracking Based on ANFIS and UKF. Proceedings of Intelligent Computation Technology and Automation, Oct 20-22 2008, Hunan, China. Los Alamitos: IEEE; 2008.

[28] Wu W, Min W. The Mobile Robot GPS Position Based on Neural Network Adaptive Kalman Filter. Proceedings of Computational Intelligence and Natural Computing, June 6-7 2009, Wuhan, China. Los Alamitos: IEEE; 2009.

[29] Lin C, Henty BE, Cooper R, et al. A Measurement Study of Time-Scaled 802.11a Waveforms Over the Mobile-to-Mobile Vehicular Channel at $5.9 \mathrm{GHz}$. IEEE Communications Magazine. 2008;46(5): 84-91.

[30] Al-Sultan S, Al-Doori MM, Al-Bayatti AH, Zedan H. A comprehensive survey on vehicular ad hoc network. Journal of Network and Computer Applications. 2014;37: 380-392.

[31] Hagan MT, Menhaj MB. Training Feedforward Networks with the Marquardt Algorithm. IEEE Transactions on Neural Networks. 1994;5(6): 989-993.

[32] Ampazis N, Perantonis SJ. Two highly efficient second-order algorithms for training feedforward networks. IEEE Transactions on Neural Networks. 2002;13(5): 1064-1074.

[33] Demuth H, Beale M, Hagan M. Neural network toolbox. $9^{\text {st }}$ ed. Natick, Mass.: MathWorks; 2010.

[34] Caveney D. Cooperative Vehicular Safety Applications. IEEE Control Systems. 2010;30(4): 38-53.

[35] Ahmed-Zaid F, Bai F, Bai S, et al. Vehicle Safety Communications - Applications (VSC-A). Final Report: Appendix Volume 1 System Design and Objective Test. CAMP DOT HS 811 492B. Washington, DC: US National Highway Traffic Safety Administration; 2014. 